\title{
The effect of farmland on the surface water of the Aral Sea Region Using Multi-Source Satellite Data
}

\author{
Jiancong Shi ${ }^{1,2}{ }^{2}$ Qiaozhen Guo ${ }^{\text {Corresp., } 1}$, Shuang Zhao ${ }^{1}$, Yiting Su ${ }^{3}$, Yanqing Shi ${ }^{1}$ \\ 1 school of geology and geomatis, Tianjin Chengjian University, Tianjin, China \\ 2 Taiyuan Design Research Institute Group Co., Ltd for Coal Industry, Taiyuan, China \\ ${ }^{3}$ College of Geoscience and Surveying Engineering, China University of Mining and Technology-Beijing, Beijing, China \\ Corresponding Author: Qiaozhen Guo \\ Email address: gqiaozhen@tcu.edu.cn
}

Background: The improper land utilization has brought tremendous pressure on the surface water of the Aral Sea Region in the past decades. It was seriously hindered for construction of the Green Silk Road Economic Belt by the fragile environment. Therefore, it is of great necessity for environmental protection and social development to monitor the change of surface water in the Aral Sea Region. Methods: In this study, LandTrendr algorithm was used on Landsat time-series data to characterize the change in farmland on the Google Earth Engine platform. Based on multi-source data, the water area changes of the Aral Sea were extracted based on the Google Earth Engine, and the mean method was utilized to extract the changes in water level and water storage. Finally, a water-farmland coupling degree model was utilized to evaluate the impact of farmland changes on the surface water in the Aral Sea Region. Results: As a result, the change of farmland is as follows: the farmland area of the Aral Sea Region has abandoned $3129 \mathrm{~km}^{2}$ from 1987 to 2019 , with overall accuracy of $85.3 \%$. The farmland change had increased the drainage downstream of the Amu Darya River and the Syr Darya River. It has led area of the Aral

Sea to decrease each year continuously. The area of the Aral Sea shrank by $1606.36 \mathrm{~km}^{2}$ per year from 1987 to 2019. Furthermore, Aral Sea's water level decreased by $0.13 \mathrm{~m}$ per year from 2003 to 2009. The amount of water storage in the Aral Sea Region also showed a downward trend from 2002 to 2016. There was a high-quality coupling coordination 0.903 relationship between surface water and farmland. It will increase the burden of water for people's normal daily life by the water loss resources caused by abandoned farmland. This study emphasized threat of unreasonable farmland management to surface water of the Aral Sea Region. The findings contributed for decision makers to formulating effective reasonable policies to protect surface water and use land of the Aral Sea Region. Meanwhile, the application of coupling degree model can provide a new method for 
studying the connection of independent systems in the farmland, water, environment and more. 
1 The Effect of Farmland on the Surface Water of the

2 Aral Sea Region Using Multi-Source Satellite Data

3

4

5

6

7

8

9

10

11

12

13

14

15

16

17

18

19

20

21

22

23

24

25

26

27

28

29

30

31

32

33

34

35

36

37

38

39

Jiancong Shi ${ }^{1,2}$, Qiaozhen Guo ${ }^{1}$, Shuang Zhao ${ }^{1}$, Yiting Su${ }^{3}$, Yanqing Shi ${ }^{1}$

${ }^{1}$ School of Geology and Geomatics, Tianjin Chengjian University, Tianjin, China

${ }^{2}$ Taiyuan Design Research Institute Group Co., Ltd for Coal Industry, Taiyuan, Shanxi, China

${ }^{3}$ College of Geoscience and Surveying Engineering, China University of Mining and

Technology-Beijing, Beijing, China

Corresponding Author:

Qiaozhen Guo $^{1}$

Jinjing Road, Xiqing District, Tianjin, 300384, China

Email address: gqiaozhen@tcu.edu.cn

\section{Abstract}

Background: The improper land utilization has brought tremendous pressure on the surface water of the Aral Sea Region in the past decades. It was seriously hindered for construction of the Green Silk Road Economic Belt by the fragile environment. Therefore, it is of great necessity for environmental protection and social development to monitor the change of surface water in the Aral Sea Region.

Methods: In this study, LandTrendr algorithm was used on Landsat time-series data to characterize the change in farmland on the Google Earth Engine platform. Based on multi-source data, the water area changes of the Aral Sea were extracted based on the Google Earth Engine, and the mean method was utilized to extract the changes in water level and water storage. Finally, a water-farmland coupling degree model was utilized to evaluate the impact of farmland changes on the surface water in the Aral Sea Region.

Results: As a result, the change of farmland is as follows: the farmland area of the Aral Sea Region has abandoned $3129 \mathrm{~km}^{2}$ from 1987 to 2019 , with overall accuracy of $85.3 \%$. The farmland change had increased the drainage downstream of the Amu Darya River and the Syr Darya River. It has led area of the Aral Sea to decrease each year continuously. The area of the Aral Sea shrank by $1606.36 \mathrm{~km}^{2}$ per year from 1987 to 2019. Furthermore, Aral Sea's water level decreased by 0.13 $\mathrm{m}$ per year from 2003 to 2009. The amount of water storage in the Aral Sea Region also showed a downward trend from 2002 to 2016. There was a high-quality coupling coordination 0.903 relationship between surface water and farmland. It will increase the burden of water for people's normal daily life by the water loss resources caused by abandoned farmland. This study emphasized threat of unreasonable farmland management to surface water of the Aral Sea Region. The findings contributed for decision makers to formulating effective reasonable policies to protect surface water and use land of the Aral Sea Region. Meanwhile, the application of coupling degree

PeerJ reviewing PDF | (2021:07:63710:3:0:NEW 19 Jan 2022) 
40 model can provide a new method for studying the connection of independent systems in the 41 farmland, water, environment and more.

\section{Introduction}

As the essential water resources in the Aral Sea Basin and even in Central Asia, the Aral Sea

44

45

46

47

48

49

50

51

52

53

54

55

56

57

58

59

60

61

62

63

64

65

66

67

68

69

70

71

72

73

74

75

76

77

78

79 could primarily ensure the stability of the surface water to be maintained (Micklin, 1988). However, the area of the Aral Sea is currently only one-tenth of that in 1960 (Wu et al., 2020). As impacted by the rapid shrinking of the Aral Sea, the surface water of the Aral Sea Basin has been severely decreased (Eleni et al., 2020). The shrinking surface water caused land desertification and land salinization (Parajuli et al., 2017), thereby seriously endangering the development of society. Accordingly, it is essential for protection of the surface water and regional development to reveal the root cause of the Aral Sea's shrinkage.

The Aral Sea Basin refers to a severely arid area with annual precipitation of less than 300 $\mathrm{mm}$ (Elena, 2014). Thus, the level of the Aral Sea is determined by the inflow of two feeding rivers, the Amu Darya and the Syr Darya (Philippe et al., 2007). The two rivers originate from the melting of snow in the mountains of southeast of the Aral Sea Basin (Micklin, 2016). Scholars have carried out researches on the upstream of Amu Darya and Syr Darya, as presented below. Valentina et al. found that the snow depth in the rivers' (e.g., the Amu Darya and the Syr Darya) source tended to decrease after 1965, whereas the runoff downstream has been declining (Valentina et al., 2009). Hagg et al. considered that the runoff of the upper reaches in the Amu Darya River would gradually increase (Hagg et al., 2007). In a word, considerable researches indicated a downtrend of snow depth in the source of the Amu Darya River and the Syr Darya River, whereas the runoff downstream has been declining (Annina et al., 2012; Wang et al., 2016). The above studies show that the upstream runoff of Amu Darya and Syr Darya increases each year, which is contrary to the shrinkage of the Aral Sea. At the same time, researchers have found that the shrinkage of the Aral Sea is directly related to the reduction of runoff downstream of rivers (Shi et al., 2021; Micklin, 2007). Therefore, this study will focus on the downstream area of rivers near the Aral Sea.

Over the past decades, unreasonable land utilization led to the decline of downstream runoff in the Amu Darya River and the Syr Darya River, which directly caused the shrinking of the Aral Sea (Christopher et al., 2016). Primarily, neighbouring countries used a lot of lands to plant farmland, and have done many radical measures to increase the value of agricultural output. For instance, the former Soviet Union built the channel with $500 \mathrm{~km}$ in the Amu Darya River area and the Syr Darya River area in 1960. Such a project took one-third of the water in rivers downstream to farmland (Conant, 2006). The mentioned measure altered the rain-fed irrigation mode of farmland in the Aral Sea Basin (Micklin, 2007). By 2010, the irrigated area of the Aral Sea Basin was 7,895,600 ha, taking up 78.6\% of planted land (data from the Central Asia Water Resources Network: www.cawater-info.net). Inefficient irrigation systems and terrible management of land utilization triggered the increase in water withdrawn from rivers. Thus, surface water protection requires the exploration of the farmland variations in the Aral Sea Basin. Several studies have been conducted on the surface water variations attributed to irrigation. For instance, Jin et al. 
80

81

82

83

84

85

86

87

88

89

90

91

92

93

94

95

96

97

98

99

100

101

102

103

104

105

106

107

108

109

110

111

112

113

114

115

116

117

118

119

investigated human irrigation-induced hydrological variations in the Aral Sea Basin by multiple satellite data (Jin et al., 2017). Fabian et al. mapped abandoned farmland to support surface water protection in Kyzyl-Orda, Kazakhstan (Fabian et al., 2015). However, existing studies could not determine a quantitative model to assess the impact of farmland changes on surface water. Accordingly, it is of great necessity to establish a method to assess the effect of farmland changes on surface water.

For the complicated political issues and poor physical accessibilities of the Aral Sea Region, there are severe limitations in collecting data required for large-scale and long-term change detection and analyses (Fabian et al., 2015). As an alternative, remote sensing technology, exhibiting the advantages in data of effective coverage of long-term span and multi-time scale, has been extensively employed in natural disaster early warning, eco-environmental protection, farmland protection, dynamic analysis of land use, social development, etc. (Tewkesbury et al., 2015; Li et al., 2003; Saha et al., 2019). Alka et al. used multi-source data to explore inter-annual water storage variations in the Aral Sea (Singh et al., 2012). Jin et al. adopted multiple satellite data to view environmental variations around the Aral Sea (Jin et al., 2017). At present, remote sensing technology has become an essential measure of long-term monitoring variations in surface water in large areas (Singh et al., 2012). However, the above researches are difficult to characterize the impact of farmland on the surface water quantitatively. Thus, this study combined the comprehensive variations of water and farmland changes to explore the internal relationship between the surface water and farmland based on multi-source data.

The water area, water level and surrounding water storage of the Aral Sea act as critical indicators to characterize the hydrological variations in the Aral Sea. Multi-source data efficiently supports extracting the comprehensive variations of water. The LandTrendr (Landsat-based Detection of Trends in Disturbance and Recovery) algorithm can capture both long-term gradual and short-term drastic variations (Gorelick et al., 2017). Moreover, Kennedy et al. encapsulated the LandTrendr on the GEE platform to consume considerable computation time in continuous change detection, (Kennedy et al., 2018). Moreover, it has been broadly applied in most fields of change detection (Zhu et al., 2019). The coupling degree model is capable of reflecting the degree of association between multiple subsystems.

This study aimed to examine the surface water attributed to land utilization change of the Aral Sea Region. The specific steps are as follows: Firstly, the LandTrendr algorithm was run on Landsat time-series of the GEE platform to detect the land utilization change modes. Second, the variations of water area, water level and water storage were detected using multi-source data (Landsat, ICESat, GRACE). Lastly, to explore the effect of farmland changes on the surface water, the variations of water (water area, water level and water storage) and farmland were combined to build a water-farmland coupling degree model. The mentioned efforts can provide explicit cognitions regarding the effect of farmland on surface water. Furthermore, it can provide practical implications for agricultural governance, water protection and surface water balance.

\section{Materials \& Methods}


120

121

122

123

124

125

126

127

128

129

130

131

132

133

134

135

136

137

138

139

140

141

142

143

144

145

146

147

148

149

150

151

152

\subsection{Study Area}

The Aral Sea Region is located on the border between northwest Uzbekistan and southwest Kazakhstan. It covers $130,000 \mathrm{~km}^{2}$, and includes North Aral, East Aral, West Aral and irrigated farmland of the Aral Sea Region (Figure 1). This is a typical arid area with an average annual temperature of $11.62^{\circ} \mathrm{C}$ and precipitation of $126.26 \mathrm{~mm}$.

Figure 1. Research scope: (a) general location in the Aral Sea Basin and the Central Asia; (b) 1987 land-use classification from Google Earth Engine (GEE) imagery

\subsection{Data Preparation}

\subsubsection{Landsat data and Pre-processing}

Landsat surface reflectance data (Landsat5, Landsat7 and Landsat8) were collected from 1984 to 2019 on GEE platform. This study used the FMASK and neighboring position filling to improve extraction accuracy to remove the mentioned poor-quality (snow/ice, clouds, building shadows and scan-line corrector (SLC)-off gaps) images (Zhu et al., 2012). Accordingly, the Landsat surface reflectance dataset was produced for our study area from 1987 to 2019 (A-LSTC). Lastly, the dataset (YA-LSTC) was synthesized into annual images from the A-LSTC (June 1 to September 1). The normalized vegetation index (NDVI) was introduced to the dataset as a new band (Tucker, 1979).

$$
N D V I=\frac{\rho_{\text {nir }}-\rho_{r}}{\rho_{\text {nir }}+\rho_{r}}
$$

Where $\rho_{\text {nir }}$ and $\rho_{\mathrm{r}}$ are the near-infrared band and red band in Landsat.

\subsubsection{ICESat satellite altimetry data}

The ICESat mission was initiated in January 2003 and ended in February 2010 by National Aeronautics and Space Administration (NASA) (Schutz et al., 2005). The Geoscience Laser Altimeter System (GLAS) on ICESat has provided global measurements of polar ice sheet mass balance, cloud and aerosol heights, land topography and vegetation characteristics with a surface sampling diameter of $70 \mathrm{~m}$ as well as a spacing of $172 \mathrm{~m}$ (Zwally et al., 2008). ICESat/GLAS level 2 altimetry product (GLA14) consists of global land surface elevation data (Kwok et al., 2004). The GLA14 has been broadly introduced in lake water level and land elevation and have reflected accuracy over $10 \mathrm{~cm}$ (Zhang et al., 2011). Thus, the GLA14 can precisely contribute to the surface elevation. The GLA14 from 2003 to 2009 were collected to extract the water level change in the Aral Sea.

\subsubsection{GRACE Data}

The Gravity Recovery and Climate Experiment (GRACE) mission was launched in March 2002 and ended in October 2017 by NASA. The water mass variations were considered a change 
153 of Earth's gravity by GRACE (Jin et al., 2017). Most gravity signals after de-noising of GRACE 154 reflect variations in water storage (Chen et al., 2019; Swenson et al., 2007). However, the orbital 155 altitude and resolution of GRACE limited the effective research range $\left(<200,000 \mathrm{~km}^{2}\right)$ (Singh et 156 al., 2012). Thus, the original research range was extended to $230,000 \mathrm{~km}^{2}$. Though the study area 157 is less than $230,000 \mathrm{~km}^{2}$, it can be assumed that the mass variations on long-time scales come from 158 the long-term storage change of water of the Aral Sea Region. Thus, the GRACE data was 159 processed in the GEE platform from 2002 to 2016 (research range between June and September 160 each year).

161

162

163

164

165

166

167

168

169

170

171

172

173

174

175

176

177

178

179

180

181

182

183

184

185

186

187

188

\subsection{Detection Algorithm}

Figure 2. Research Method: (a) The method of farmland change detection; (b) The method of water change detection; (c) The method coupling degree model.

\subsubsection{Detection Algorithm of Farmland Change}

LandTrendr (Landsat-based Detection of Trends in Disturbance and Recovery) algorithm is an approach to extract the spectral trajectories of land surface from Landsat time-series stacks (Watts et al., 2014). This algorithm can reflect farmland variations by detecting the temporalspectral trajectory of each pixel. The input of every pixel for the algorithm is a time series with one spectral value or index. This algorithm also needs to set parameters, such as noise-induced spikes (outliers), potential vertices (breakpoints), fitting trajectories, and the optimal number of segments (Watts et al., 2014).

LandTrendr algorithm on the GEE platform was used to detect the farmland change in the Aral Sea Region (Figure 2-(a)). Before running this algorithm, the features of farmland variations were analyzed, tested different combinations of parameter values. The NDVI was determined as the spectral index, and other parameters were calculated (Table S1). NDVI of farmland ranged from 0.45 to 0.69 in the Aral Sea Region and plummeted after abandonment to range from 0.2 to 0.3 . Thus, NDVI of abandoned farmland was set between 0.2 and 0.3 . The mentioned thresholds were adopted to detect the change patterns of farmland, the change time of occurrence and end, and duration.

Table S1. Operating parameters of LandTrendr

\subsubsection{Detection Algorithm of Waters Change}

Via the GEE platform, the random forest algorithm was adopted to detect the variation of water area (Figure 2-(b)). Random forest is a machine learning algorithm that is complies with the decision tree. This algorithm uses CART clustering for prediction and classification (Breiman, 2001). Two primary parameters should be set before implementing the random forest algorithm. To be specific, the first refers to the number of splitting times (mtry) of the branch tree in each

Peer] reviewing PDF | (2021:07:63710:3:0:NEW 19 Jan 2022) 
189

190

191

192

193

194

195

196

197

198

199

200

201

202

203

204

205

206

207

208

209

210

211

212

213

model. This parameter should be set as the square root value of variables and 2 times or $1 / 2$ of the prediction's open value. In this paper, the variables specifically refer to the bands of remote sensing images (Table S2). The second refers to the number of generated trees (ntree) in model operation, and the amount of model calculation is proportional to the value of ntree. The ntree was set as 500 because it will be pretty obvious with a bit of tinkering that the predictions from the model will not change much after this value.

The accuracy of model depends more on quality of training samples. Therefore, we selected 200 pixels representing water and another 200 pixels representing non-water based on Landsat imagery. In order to access accuracy of results, we visually examined all selected pixels (from 1987 to 2019) and used high-spatial-resolution Google Earth imagery for further manual interpretation of land cover (Figure 3). Therefore, we determined and recorded whether and when water pixels change occurred.

Table S2. Variables of Random Forest Algorithm

Figure 3. Examples areas of water change and farmland change near the Syr Darya and the Amu Darya. Figures a1 and a2 represent the water change years 2009 and 2019; Figures b1, b2, b3 represent the water change years 2009, 2016 and 2019.

The ICESat data was adopted to analyze the alteration in water level in the Aral Sea. At first, the data format of GLA14 was converted. Second, GLA14 was adopted to extract the water level of the Aral Sea (Eq. 2). Lastly, the water volume was calculated according to the alteration in water level and the variation of water area of the Aral Sea (Eq. 3). Meanwhile, researchers compared ICESat data with airborne LiDAR data and DEM from GPS data. The error of ICESat data is less than $3 \mathrm{~cm}$ (Kurtz et al., 2008; Fricker, 2005).

$$
\begin{gathered}
\mathrm{WL}_{\mathrm{T}}=\frac{\sum_{i=1}^{n} w l}{n} \\
W V=W L_{T} * W A
\end{gathered}
$$

214

215

216

217

218

219

220

221

222

Where $\mathrm{WL}_{\mathrm{T}}$ is mean water level. wl is the land elevation of every ICESat point. WV is water volume. WA is water area.

The GRACE dataset was used to extract the equivalent water height $(\mathrm{EWH})$. The data contained in this dataset are units of "Equivalent Water Thickness" which represent the deviations of mass in terms of the vertical extent of water in centimeters (Watkins et al., 2015). The EWH was processed at NASA Jet Propulsion Laboratory. Actually, this dataset was produced by three institutions: CSR (U. Texas / Center for Space Research), GFZ (German Research Center for Geosciences), and JPL (NASA Jet Propulsion Laboratory). However, since each institution independently produces the coefficients, the results may be slightly different. And the mass change 
223 maps of the three institutions have typically suffered from poor observability of east-west 224 gradients, resulting in "N-S stripes" that are conventionally removed via empirical smoothing 225 and/or "destriping" algorithms. In order to overcome these limitations, Watkins et al., developed 226 GRACE(-FO) mass concentration (mascon)solutions (Watkins et al., 2015; Wiese et al., 2016; 227 Landerer et al., 2020). The solutions allow for convenient application of a priori information 228 derived from near-global geophysical models to prevent striping. Significantly, over the land, 229 mascon solutions have more excellent resolution for smaller spatial regions, in particular when 230 studying secular signals. Meanwhile, for different application scenarios, the dataset has its 231 advantages. For instance, it is more suitable for water, ice mass, and ocean bottom pressure mass 232 change application to use JPL mascon (Watkins et al., 2016; Landerer et al., 2020). Therefore, JPL 233 data, which have been processed by the GRACE(-FO) mascon solutions, were used in this paper. 234 And the measurement accuracy of GRACE data is credible (5000km wavelength: $0.001 \mathrm{~mm}$; $235500 \mathrm{~km}$ wavelength: $0.01 \mathrm{~mm}$ ) (Zheng et al., 2009). Water storage variation in the Aral Sea Region 236 was analyzed (Eq. 4).

$$
W S=E W H T * A
$$

237 238

239

240

241

242

243

244

245

246

247

248

249

250

251

252

253

254

255

256

257

258

Where EWHT is the equivalent water height from GRACE dataset; WS is water storage; A is the area of study region.

\subsection{Accuracy Assessment}

Two hundred pixels were selected to build a confusion matrix (CM) to assess the accuracy of the five surface features in 1987 (i.e., water, farmland, desert, shoal and irrigation land). Meanwhile, we visually examined all surface features by high-spatial-resolution Google Earth imagery. The overall accuracy, user accuracy, and producer accuracy for each feature were concluded following the indexes defined by Foody and Green (Congalton et al., 1993; Foody, 2002). Two hundred validating pixels were selected to represent the stable area of farmland. In addition, another 200 validating pixels represent the various area of farmland for each change mode. The stable area refers to the pixels that remain unchanged as farmland for years. While the various area represents the changed farmland pixels during the whole study period. The $20 \%$ pixels of training samples in water extraction were adopted to produce a CM to access the accuracy of water extraction results.

\subsection{Water-Farmland Coupling Degree Model}

The coupling degree model originated from the coupling coefficient model in physics. Farmland and surface water were combined to build the water-farmland coupling degree model to explore the impact of farmland on surface water. In such a model, four indicators were selected related to surface water and farmland (Figure 2-(c)). At first, every indicator was normalized, and then the entropy method was used to determine their weight. The index matrix is $X=\left(x_{a b}\right)_{i \times j}$ (where $\mathrm{i}$ is the evaluation index; $\mathrm{j}$ is the index, and $x_{a \mathrm{~b}}$ is the $\mathrm{b}$-th index of the a-th sample,). The coupling degree model (C) is as follows (Chang, 2018). 


$$
\begin{gathered}
C=\left\{\frac{f_{1}(x) * \cdots * f_{i}(x)}{\left|\frac{f_{1}(x)+\cdots+f_{i}(x)}{i}\right|^{i}}\right\}^{1 / i} \\
f_{i}(x)=\sum_{b}^{j} w_{b} x_{b}
\end{gathered}
$$

259

260

261

262

263

264

265

266

267

268

269

270

271

272

273

274

275

276

277

278

279

280

281

282

283

284

285

286

Where $f_{i}(x)$ is the comprehensive evaluation function of subsystem; $w_{\mathrm{b}}$ is the weight of each index; $x_{b}$ is each index; $i$ is the number of subsystems to be access. There are two subsystems which need to be evaluated, so $i=2$. $(C \in[0,1])$. If the $C$ value is closer to 1 , it will mean that the subsystems are more related and coordinated (Congalton et al., 1993).

\section{Results}

\subsection{Accuracy Assessment}

The CM for the classification of 1987 imagery (Table S3) revealed that the overall accuracy (OA) reached over $90 \%$. The user accuracy (UA), and producer accuracy (PA) for each class mainly were more than $86 \%$. The accuracy of farmland is less than $90 \%$. The reasons are elucidated below. There were considerable irregular water bodies and farmland in irrigated land of the Aral Sea Region; thus, the farmland often tended to mix with water and Irrigation land. Moreover, some sparse vegetation was planted in the irrigation land. Thus, it was difficult to distinguish by employing Landsat images with a spatial resolution of $30 \mathrm{~m}$. However, the overall accuracy reached $92.1 \%$, suggesting the random forest model's capability. A similar method was used to assess the accuracy of extraction of water area in the Aral Sea from 1987 to 2019. The accuracy of extraction of water area reached over $90 \%$, demonstrating the credibility of the results.

Table S3. Confusion matrix for the 1987 classified image.

Table S4 show the farmland detection accuracy of abandon and replanting by LandTrendr. The overall accuracy of $85.3 \%$ was low for abandoned farmland for the mixture of abandoned farmland and sparse planting. For the replanting, the PA, UA, and OA are above $80 \%$. Thus, it is sufficient for farmland to detect the change model. In summary, the OA of abandoned farmland change detection was more than $85 \%$, demonstrating the detection method's reliability based on the LandTrendr.

Table S4. Confusion matrix for the change detection of abandoned farmland. 
287

288

289

290

291

292

293

294

295

296

297

298

299

300

301

302

303

304

305

306

307

308

309

310

311

312

313

314

315

316

317

318

319

320

321

322

323

324

\subsection{Temporal and Spatial Variations of Farmland}

The distribution of abandoned farmland, in the Aral Sea Region during 1987-2019, was rendered the disturbance map with a gradient (Figure 4) according to the occurrent years. The abandoned region was mainly diffused around the Syr Darya and the Amu Darya, especially around the Amu Darya (Table S5). Within $9 \mathrm{~km}$ of these Draya rivers, the percentage of abandoned farmland reached $59.96 \%$ from 1987 to 2019 . Overall, $3129 \mathrm{~km}^{2}$ of farmland was abandoned. The annual change peaked between 1987 and 1993 (Table S6), after which percentage of abandoned farmland decreased under 3\% from 2002 to 2016 (Table S6). However, the percentage of abandoned farmland was elevated to $5.7 \%$ in 2017 (Table S6), which resulted in the plummet of water volume in the Aral Sea.

Figure 4. Year of abandoned farmland in the Aral Sea Region with two areas shown in detail: (a) Around the Syr Darya River; (b) Around the Amu Darya River.

Table S5. Area of Abandoned Farmland near the Amu Draya and the Syr Draya

Table S6. Area of Abandoned Farmland in the Aral Sea Region

\subsection{Waters Variations of the Aral Sea Region}

The Aral Sea has been shrinking at $1606.36 \mathrm{~km}^{2}$ per year from 1987-2019. In 2019, the area of the Aral Sea took up only $15.6 \%$ of its size in 1987 (Figure 5). With an annual decrease of $1306.18 \mathrm{~km}^{2}$, the East Aral $\left(820.22 \mathrm{~km}^{2}\right)$ had almost dried up by 2019 . The area of the East Aral, in 2019 , only accounted for $1.92 \%$ in 1987 . On the contrary, as impacted by the construction of the Dike Kokaral dam in 2005, the North Aral showed a weak expansion trend with an average annual growth of $10.05 \mathrm{~km}^{2}$. The area of North Aral rose to $4658.773 \mathrm{~km}^{2}$ in 2019 . Kazakhstan Government built the Kokaral dam at the junction of the North Aral and East Aral (Figure 5). In order to keep the water level of North Aral and environment stable, the water flow from North Aral to East Aral was artificially reduced. Though this policy effectively prevented the loss of North Aral, it also reduced the water flowing into East Aral. Such a dam aggravated the dry-up of East Aral. The West Aral is small and far from the irrigated area. Accordingly, the West Aral had shrunk more minor than the East Aral at $314.83 \mathrm{~km}^{2}$ each year.

Figure 5. Change of the Aral Sea area from 1987 to 2019: (a) the spatial distribution; (b) the temporal distribution.

Likewise, the water level of the Aral Sea tended to decrease. The curve of the water level of the North Aral significantly ascended as impacted by the construction of the dam (Figure 6). The water level of the North Aral was elevated near $0.32 \mathrm{~m}$ per year from 2003 to 2009. In the East Aral, the water level drastically declined at $0.5 \mathrm{~m}$ per year. Moreover, the East Aral was only 0.05 
325

326

327

328

329

330

331

332

333

334

335

336

337

338

339

340

341

342

343

344

345

346

347

348

349

350

351

352

353

354

355

356

357

358

359

360

$m$ in 2019. Compared with the East Aral, declining West Aral was lower as impacted by its smaller range and farther from the irrigated area. To be specific, the water level of the West Aral decreased at $0.4 \mathrm{~m}$ per year and dropped to $2.1 \mathrm{~m}$ in 2019 .

Figure 6. Change of the Aral Sea water level from 2003 to 2009.

Figure 7 illustrates the water mass change of the GRACE analysis in the study area. The curve of equivalent water height shows a downward trend from 2002 to 2016 . The change of equivalent water height is same as the water level. The water mass was overall declining, marking a decrease by $0.97 \mathrm{~km}^{3}$ each year. The decrease in water mass represented the descending of water storage, such as the Aral Sea, rivers, reservoirs and groundwater.

Figure 7. Mass change of the Aral Sea Region from 2002 to 2016.

\subsection{Construction of Water-Farmland Coupling Degree Model}

According to the results of this study regarding water and farmland in the Aral Sea Region, three indexes were selected to build a comprehensive evaluation index system (Table S7). This system included two subsystems (surface water system, farmland system). Water subsystem had two evaluation indexes, and farmland subsystem had one evaluation index (Table S7).

The entropy method was adopted to calculate the weight of each index. According to the mentioned weights, the coupling degree was obtained between the two subsystems from 2003 to 2009. In addition, the results indicated that the annual coupling degree value was above $70 \%$, and the average coupling degree reached 0.903 (Table S8). By the criterion of coupling degree (Table S9) (Chang, 2018), only 2003 and 2005 pertain to intermediate level coupling coordination. Other years belong to high-quality coupling coordination. In addition, the average coupling degree belongs to the high-quality coupling coordination. The mentioned coupling degree results suggested that the greater coupling degree between the two subsystems, and farmland changes affected the variations of surface water in the Aral Sea Region.

Table S7. Comprehensive evaluation index system of water and farmland coupling degree.

Table S8. Weight of every index, coupling degree value of every year and average coupling degree value.

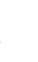

(a)

Table S9. Criteria for Coupling Coordination Type

\section{Discussion}


361

362

363

364

365

366

367

368

369

370

371

372

373

374

375

376

377

378

379

380

381

382

383

384

385

386

387

388

389

390

391

392

393

394

395

396

397

398

\subsection{Benefits of Methods}

The results shown that, the loss of water by abandoned farmland will increase the burden of normal water use. During the past years, many scholars were committed to analyzing the reasons for the decrease of surface water in the Aral Sea Region. Compared with previous researches, our work has similarities and differences. For similarities, the surface water loss was caused by improper irrigation management. On the contrary, our research was from the perspective of farmland abandonment. Few studies have analyzed the loss of water caused by abandoned farmland. They were analyzed effect of land water storage on surface water (Jin et al. 2017; Gaybullaev et al, 2012; Parajuli et al. 2017).

The coupling degree model was used for the first time to monitor the effect of farmland on the surface water of the Aral Sea Region. Most previous researches regarded farmland and surface water as independent objects, which could not acquire the natural connection between them. Therefore, changes in farmland and surface water were put into a quantifiable system that can be used to explore the substantial impact of farmland changes on the surface water. According to the result, the coupling degree model showed good applicability in this field. In addition, it could provide a new method for the internal connection between farmland, surface water, and ecology in the Aral Sea Region and even the Aral Sea Basin.

\subsection{Effect of Abandoned Farmland on Surface Water in Aral Sea Region}

The abandoned farmland will cause a lot of surface water loss. The main reason is that irrigation canals of abandoned farmland are not blocked because of the negligence of management. It directly led to majority of the water was being soaked up by the desert and blatantly loss (Ibragimov et al, 2007; Maksud et al, 2016; Jabbarov et al, 2013). According to the results of section 3.2, we extracted the area of abandoned farmland (Table S6). The area of abandoned farmland reached per year $97.843 \mathrm{~km}^{2}$. And the abandoned farmland will cause a lot of water waste. Farmland in Aral Sea Region is concentrated on planting cotton, wheat and rice (Chapagainet al., 2005). Table S10 shows that wheat is the thirstiest crop. And the water use efficiency of cotton is the lowest $\left(0.451 * 108 \mathrm{~kg} / \mathrm{km}^{3}\right)$. Table S11 shows the crop production in precious decades.

Table S10. Crop Water use efficiency in Aral Sea Region.

Table S11. Crop production in the Aral Sea Region.

Based on the above results, the loss volume of water loss by abandoned farmland can be extracted. If all the abandoned farmland were used to plant cotton in the past few years, the water loss would reach $0.028 \mathrm{~km}^{3}$ every year (Table S12). According to the current distribution of available water per capita from the World Bank (Uzbekistan, $2596 \mathrm{~m}^{3} /$ per person / annually;

Peer) reviewing PDF | (2021:07:63710:3:0:NEW 19 Jan 2022) 
399

400

401

402

403

404

405

406

407

408

409

410

411

412

413

414

415

416

417

418

419

420

421

422

423

424

425

426

427

428

429

430

431

432

433

434

435

436

437

Kazakhstan, $1943 \mathrm{~m}^{3} /$ per person / annually), the water loss can provide annual domestic water for tens of thousands of people in the Aral Sea Region. The specific numbers are as follows: Kazakhstan are 14410 persons, and Uzbekistan are 10785 persons. Therefore, abandoned farmland caused additional loss of normal domestic water for people in the Aral Sea Region.

Table S12. Water Consumption for Planting Cotton in Abandoned Farmland.

The previous researches gave us much inspiration. Micklin macroscopically analyzed the reason and effect of water changes in the Aral Sea (Micklin, 2010). Yoshihiro et al. found nearly $100 \%$ return flows of the applied irrigation water in the Aral Sea Drainage Basin (Yoshihiro et al., 2007). Cretaux et al. analyzed effect of groundwater on the hydrological water budget of the Aral Sea by remote sensing data (Cretaux et al., 2013). Compared with above researches, our contributions are as follows:

1. Based on the coupling degree model, we quantitatively characterized the effect of farmland changes on surface water.

2. The coupling degree model was used for the first time to study the effect of farmland changes on surface water. We believe that this attempt will help broaden the thinking of researchers in the fields of remote sensing, environment and more. They can connect independent systems through the coupling degree model.

3. The effect mechanism was analyzed on surface water changes by calculating the amount of water loss in abandoned farmland. Moreover, the normal domestic water for people caused by water loss was analyzed.

\subsection{Limitations of Research}

At first, vegetation indices can reduce other factors' impacts in monitoring land cover change (Zhang et al., 2013). The NDVI can reduce the influence of external environmental factors on the surface reflectance to some extent. Previous studies indicated that the accuracy of NDVI in detecting farmland is better than others (Tong et al., 2017). However, due to the disturbance by other vegetation in the arid region, using NDVI to the LandTrendr algorithm has some limitations (Watts et al., 2014). A typical example is that the sparse vegetation of the Aral Sea Region generated the same NDVI signal with farmland and affected the detection results. Therefore, it is necessary to add additional indices to improve accuracy.

Secondly, the data on water level and water storage cannot match the water area's time series. However, this fusion of data yet offers valuable and unique information on the surface water. Simultaneously, in the next step of our research, we need to improve data integrity of the surface water.

\section{Conclusions}

In this study, the farmland variations were detected by using LandTrendr algorithm based on the GEE platform. Subsequently, multi-source data (Landsat, ICESat, GRACE) were employed to 
438 extract the variations of water area, water level, water storage in the Aral Sea Region. Given the

439

440

441

442

443

444

445

446

447

448

449

450

451

452

453

454

455

456

457

458

459

460

461

462

463

464

465

466

467

468

469

470

471

472

473

474

475

476

mentioned results, the Water-Farmland assessment was developed. Such a system assessed the impact of farmland on surface water in the Aral Sea Region. The specific results are elucidated below:

Throughout the research, the abandoned farmland areas covered $98 \mathrm{~km}^{2}$ per year. The overall accuracy of abandon took up $85.3 \%$. There was most abandoned farmland near the rivers (the Amu Darya River and the Syr Darya River) from 1987 to 2019 of the Aral Sea Region (Section 3.2). The abandon of farmland had triggered a massive loss of water resources of the Aral Sea Region.

Second, the Aral Sea shrank by $1606.36 \mathrm{~km}^{2}$ per year from 1987 to 2019, in which the East Aral shrank most seriously. Furthermore, the Aral Sea's water level was down-regulated by 0.13 m per year from 2003 to 2009, especially the East Aral. However, as impacted by the construction, Dike Kokaral dam in 2005, the water level and area curves in the North Aral started to elevate after 2005. Moreover, the amount of water storage in the Aral Sea Region declined from 2002 to 2016.

The coupling degree model overall considers the variations in surface water and farmland. In addition, the average coupling degree value exhibits high-quality coupling coordination, demonstrating that farmland changes significantly impact the surface water. Meanwhile, the volume of water loss by abandoned farmland caused additional loss of normal domestic water for people. Such a method can be referenced to investigate the effect of farmland on surface water or other fields. Moreover, the mentioned results are capable of helping relevant researchers gain insights into the effect of variations in farmland on surface water deterioration in this region, and offer sufficient support for subsequent governance and research.

\section{Acknowledgements}

\section{References}

Annina, S., Tobias, B., Markus, S., Olga, S. and Martin, B. 2012. Climate change impacts on glaciers and runoff in Tien Shan (Central Asia). Nature Climate Change, 2(10), 725-731. doi:10.1038/nclimate1592

Breiman, L. 2001. Random Forests. Machine Learning, 45(1), 5-32. doi:10.1023/A:1010933404324

Chang, Y. M. 2018. System coupling model and evaluation of water re-sources environment and urban eco-economy. Water Resources and Power, 36: 55-58.

Chapagain, A.K., R. Gautam, and A.Y. Hoekstra. 2005. "The Water footprint of cotton consumption," UNESCO- IHE, The Institute of Water Education.

Chen, H., Zhang, W. C., Ning, Nie, N. and Guo, Y. D. 2019. Long-term groundwater storage variations estimated in the Songhua River Basin by using GRACE products, land surface models, and in-situ observations. Science of the Total Environment, 649, 372-387. doi:10.1016/j.scitotenv.2018.08.352 
477 Christopher, C., Sarsh, S. S., Fabian, L., Denis, S. and Heiko, P. 2016. Cropping intensity in the 478 Aral Sea Basin and its dependency from the runoff formation 2000-2012. Remote Sensing, 8(8), 479 630. doi:10.3390/rs8080630

480 Conant, E. 2006. Return of the Aral Sea. Discover.

481 Congalton, R.G. and Green, K. 1993. Practical look at the sources of confusion in error matrix 482 generation. Photogramm. Eng. Remote Sens, 59(5), 641-644.

483 Cretaux, Jean-François, René Letolle, and Muriel Bergé-Nguyen. 2013 "History of Aral Sea 484 level variability and current scientific debates." Global and Planetary Change, 110: 99-113, doi: 485 10.1016/j.gloplacha.2013.05.006.

486 Elena, L. 2014. A multi-scale assessment of human vulnerability to climate change in the Aral 487 Sea basin. Environmental Earth Sciences, 73(2), 719-729. doi:10.1007/s12665-014-3104-1

488 Eleni, F., Maria, T., Lena, H., Antonis, A., Rene, H., Kathrin, W. and Charalampos, V. 2020. 489 Water-related ecosystems' mapping and assessment based on remote sensing techniques and 490 geospatial analysis: The SWOS national service case of the Greek Ramsar sites and their 491 catchments. Remote Sensing of Environment, 245, 111795. doi: 10.1016/j.rse.2020.111795

492 Fabian, L., Elisabeth F., Iskandar, A., Christopher, C. and John P.A. 2015. Mapping abandoned 493 agricultural land in Kyzyl-Orda, Kazakhstan using satellite remote sensing. Applied Geography, 494 62, 377-390, doi: 10.1016/j.apgeog.2015.05.009

495 Foody, G.M. 2002. Status of land cover classification accuracy assessment. Remote Sensing of 496 Environment, 80(1), 185-201. doi:10.1016/s0034-4257(01)00295-4

497 Fricker, H. A. 2005. Assessment of ICESat performance at the salar de Uyuni, Bolivia. 498 Geophysical Research Letters, 32(21): L21S06, doi: 10.1029/2005GL023423.

499 Gaybullaev, B.; Chen, S.C.; Gaybullaev, D. 2012. Changes in water volume of the Aral Sea after 500 1960. Applied Water Science, 2: 285-291. doi: 10.1007/s13201-012-0048-zGorelick, N., 501 Hancher, M., Dixon, M., Ilyushchenko, S., Thau, D. and Moore, R. 2017. Google Earth Engine: 502 Planetary-scale geospatial analysis for everyone. Remote Sensing of Environment, 202, 18-27, 503 doi: 10.1016/j.rse.2017.06.031

504 Hagg, W., Braun, L. N., Kuhn, M. and Nesgaard, T. I. 2007. Modelling of hydrological response 505 to climate change in glacierized Central Asian catchments. Journalof Hydrology, 332(1-2), 40506 53. doi: 10.1016/j.jhydrol.2006.06.021

507 Ibragimov, N., Steven R. E., Yusupbek E., Bakhtiyor S. K., Lutfullo M., John P.A. L. 2007.

508 Water Use efficiency of irrigated cotton in Uzbekistan under drip and furrow. Agricultural Water 509 Management, 90(1-2): 112-120. doi: 10.1016/j.agwat.2007.01.016

510 Jabbarov, Eshchanov, Nurmetov, Alexandra L., Margaret S., John P.A. L. 2013. Canal lining to 511 increase water use efficiency and remediate groundwater levels in Khorezm Uzbekistan, Central 512 Asia. International Journal of Agriculture: Research and Review, 3: 742-750. doi:

513 10.1039/DT9960002261

514 Jin, Q. J., Wei, J. F., Yang, Z. L. and Lin, P. R. 2017. Irrigation-Induced Environmental Changes 515 of adjacent the Aral Sea: An Integrated View from Multiple Satellite Observations. Remote

516 Sensing, 9(9), 900. doi:10.3390/rs9090900 
517 Kennedy, R.E., Yang, Z. Q., Gorelick, N., Braaten, J., Cavalcante, L., Cohen, W.B. and Healey, 518 S. 2018. Implementation of the LandTrendr Algorithm on Google Earth Engine. Remote

519 Sensing, 10(5), 691. doi:10.3390/rs10050691

520 Kurtz, N., T. Markus, D. Cavalieri, W. Krabill, J. Sonntag, Jeffrey A. Miller. 2008. Comparison

521 of ICESat Data with Airborne Laser Altimeter Measurements Over Arctic Sea Ice. IEEE

522 Transactions on Geoscience and Remote Sensing, 46(7):1913-1924.

523 doi:10.1109/TGRS.2008.916639.

524 Kwok, R., Zwally, H. J. and Yi, D. H. 2004. ICESat observations of Arctic sea ice: A first look.

525 Geophysical Research Letters, 31(16), L16401. doi:10.1029/2004g1020309

526 Landerer, F. W., Flechtner, F. M., Save, H., Webb, F. H., Bandikova, T., Bertiger, W. I.,

527 Bettadpur S V, Byun S H, Dahle C, Dobslaw H, Fahnestock E, Harvey N, Kang Z, Kruizinga G

528 L. H., Loomis Bryant D., Mccullough C, Murböck M, Nagel, P, Paik M, Pie N, Poole S,

529 Strekalov D, Tamisiea M E., Wang F, Watkins M M., Wen H Y, Wiese D N., Yuan D N. 2020.

530 Extending the global mass change data record: GRACE Follow-On instrument and science data

531 performance. Geophysical Research Letters, 47(12), doi:10.1029/2020GL088306.

532 Li, J. and Narayanan, R. M. 2003. A Shape-Based Approach to Change Detection of Lakes

533 Using Time Series Remote Sensing Images. IEEE Transactions on Geoscience

534 and Remote Sensing ,41(11), 2466-2477. doi:10.1109/tgrs.2003.817267

535 Maksud B., Claudia R., Anik B., Marc J. 2016. Optimizing irrigation efficiency improvements in

536 the Aral Sea Basin. Water Resources and Economics, 13: 30-45. doi: 10.1016/j.wre.2015.08.003

537 Micklin, P. 2007. The Aral Sea disaster. Annual Review of Earth and Planetary Sciences, 35,

538 47-72. doi: 10.1146/annurev.earth.35.031306.140120

539 Micklin, P. 2016. The future Aral Sea: hope and despair. Environmental Earth Sciences, 75(9),

540 1-5. doi: 10.1007/s12665-016-5614-5

541 Micklin, P. P. 1988. Desiccation of the Aral Sea: A water management Disaster in the Soviet

542 Union. Science, 241(4870), 1170-1176. doi:10.1126/science.241.4870.1170

543 Micklin, P. 2010. "The past, present, and future Aral Sea.", Lakes \& Reservoirs: Research \&

544 Management, 15(3): 193-213, doi: 10.1111/j.1440-1770.2010.00437.x.

545 Parajuli, S. P. and Yang, Z. L. 2017. Understanding dust emission in the Bodélé region by

546 extracting locally mobilized dust aerosols from satellite Aerosol Optical Depth data using

547 principal component analysis. Aeolian Research, 24, 105-113. doi: 10.1016/j.aeolia.2017.01.001

548 Philippe, S., Speranta, M. P., Stefan, K., Jean, P. S. and Hedi, O. 2007. Climate variability in the

549 Aral Sea basin (Central Asia) during the late Holocene based on vegetation changes.

550 Quaternary Research, 67(3), 357-370. doi: 10.1016/j.yqres.2006.11.006

551 Saha S., Bovolo, F. and Bruzzone, L. 2019. Unsupervised Deep Change Vector Analysis for

552 Multiple-Change Detection in VHR Images.IEEE Transactions on Geoscience

553 and Remote Sensing ,57, 3677-3693, doi:10.1109/tgrs.2018.2886643

554 Schutz, B. E., Zwally, H. J., Shuman, C. A. and Hancock, D. 2005. Overview of the ICESat

555 Mission. Geophysical Research Letters, 32(21), 97-116. doi:10.1029/2005GL024009

Peer] reviewing PDF | (2021:07:63710:3:0:NEW 19 Jan 2022) 
556 Shi H, Luo G, Zheng H, Chen C, Qlaf H, Bai J, Liu T, Liu S, Xue J, Cai P, He H, Uchenna F O, 557 Tim V, Philippe D. 2021. A novel causal structure-based framework for comparing a basin-wide 558 water-energy-food-ecology nexus applied to the data-limited Amu Darya and Syr Darya river 559 basins. Hydrology and Earth System Sciences, 25(2):901-925, doi: 10.5194/hess-25-901-2021.

560 Shibuo, Yoshihiro, Jerker Jarsjö, and Georgia Destouni. 2007. "Hydrological responses to 561 climate change and irrigation in the Aral Sea drainage basin." Geophysical Research

562 Letters,34(21), doi: 10.1029/2007GL031465.

563 Singh, A., Seitz, F. and Schwatke, C. 2012. Inter-annual water storage changes in the Aral Sea 564 from multi-mission satellite altimetry, optical remote sensing, and GRACE satellite gravimetry. 565 Remote Sensing of Environment, 123, 187-195. doi: 10.1016/j.rse.2012.01.001

566 Swenson, S. and Wahr, J. 2007. Multi-sensor analysis of water storage variations of the Caspian 567 Sea. Geophysical Research Letters, 34(16), L16401. doi:10.1029/2007g1030733

568 Tewkesbury, A., Comber, A., Tate, N. J., Lamb, A. and Fisher, P. F. 2015. A critical synthesis of 569 remotely sensed optical image change detection techniques, Remote Sensing of Environment, 570 160, 1-14. doi: 10.1016/j.rse.2015.01.006

571 Tong, X., Brandt, M., Hiernaux, P., Herrmann, S.M., Feng, T., Prishchepov, A.V. and Fensholt, 572 R. 2017. Revisiting the coupling between NDVI trends and cropland changes in the Sahel 573 drylands: A case study in western Niger. Remote Sensing of Environment, 191, 286-296. doi:

574 10.1016/j.rse.2017.01.030

575 Tucker, C. J. 1979. Red and photographic infrared linear combinations for monitoring 576 vegetation. Remote Sensing of Environment, 8(2), 127-150. doi:10.1016/0034-4257(79)90013-0

577 Valentina, K. and Ladislav, H. 2009. Snow cover characteristics in the Aral Sea Basin from 578 different data sources and their relation with river runoff.Journal of Marine Systems, 76(3), 254579 262. doi: 10.1016/j.jmarsys.2008.03.012

580 Wang, X. L., Luo, Y., He, C. S. and Liu, S. Y. 2016. Attribution of Runoff Decline in the Amu 581 Darya River in Central Asia during 1951-2007. Journalof Hydrometeorology, 17(5),1543-1560. 582 doi:10.1175/jhm-d-15-0114.1

583 Watkins, M. M., D. N. Wiese, D.-N. Yuan, C. Boening, and F. W. Landerer. 2015. Improved 584 methods for observing Earth's time variable mass distribution with GRACE using spherical cap 585 mascons. Journal of Geophysical Research-Solid Earth, 120, doi:10.1002/2014JB011547.

586

587

588

589

590

591

592

593

594
Watts, L.M. and Laffan, S.W. 2014. Effectiveness of the BFAST algorithm for detecting vegetation response patterns in a semi-arid region. Remote Sensing of Environment, 154, 234245. doi: 10.1016/j.rse.2014.08.023

Wiese, D. N., F. W. Landerer, and M. M. Watkins. 2016. Quantifying and reducing leakage errors in the JPL RL05M GRACE mascon solution, Water Resources Research, 52, 7490-7502, doi:10.1002/2016WR019344.

Wu, T., Sang, S., Wang, S., and Yang, Y. Y. 2020. Remote sensing assessment and spatiotemporal variations analysis of ecological carrying capacity in the Aral Sea Basin. Science of the Total Environment, 735,139562. doi: 10.1016/j.scitotenv.2020.139562 
595 Zhang, G. Q., Xie, H. J., Kang, S. C., Yi, D. H. and Ackley, S. F. 2011. Monitoring lake level 596 changes on the Tibetan Plateau using ICESat altimetry data (2003-2009). Remote Sensing of 597 Environment, 115(7), 1733-1742. doi: 10.1016/j.rse.2011.03.005

598 Zhang, Y., Gao, J., Liu, L., Wang, Z., Ding, M. and Yang, X. 2013. NDVI-based vegetation 599 changes and their responses to climate change from 1982 to 2011: A case study in the Koshi 600 River Basin in the middle Himalayas. Global and Planetary Change, 108, 139-148, doi:

601 10.1016/j.gloplacha.2013.06.012

602 Zheng W, Xu H Z, Zhong M, Yuan M J. 2009. Accurate and rapid error estimation on global 603 gravitational field from current GRACE and future GRACE Follow-On missions. Chinese 604 Physics B, 18(8):3597-3604, doi: 10.1088/1674-1056/18/8/077.

605 Zhu, L. H., Liu, X. N., Wu, L., Tang, Y. B. and Meng, Y. Y. 2019. Long-Term Monitoring of 606 Cropland Change near Dong ting Lake, China, Using the LandTrendr Algorithm with Landsat 607 Imagery. Remote Sensing, 11(10), 1234. doi: 10.3390/rs11101234

608 Zhu, Z. and Woodcock, C. E. 2012. Object-based cloud and cloud shadow detection in Landsat 609 imagery. Remote Sensing of Environment, 118, 83-94. doi: 10.1016/j.rse.2011.10.028

610 Zwally, H. J., Yi, D. H., Kwok, R. and Zhao, Y. H. 2008. ICESat measurements of sea ice 611 freeboard and estimates of sea ice thickness in the Weddell Sea, Journal of Geophysical

612 Research, 113(C2), C02S15, doi:10.1029/2007jc004284 
Figure 1

Research scope

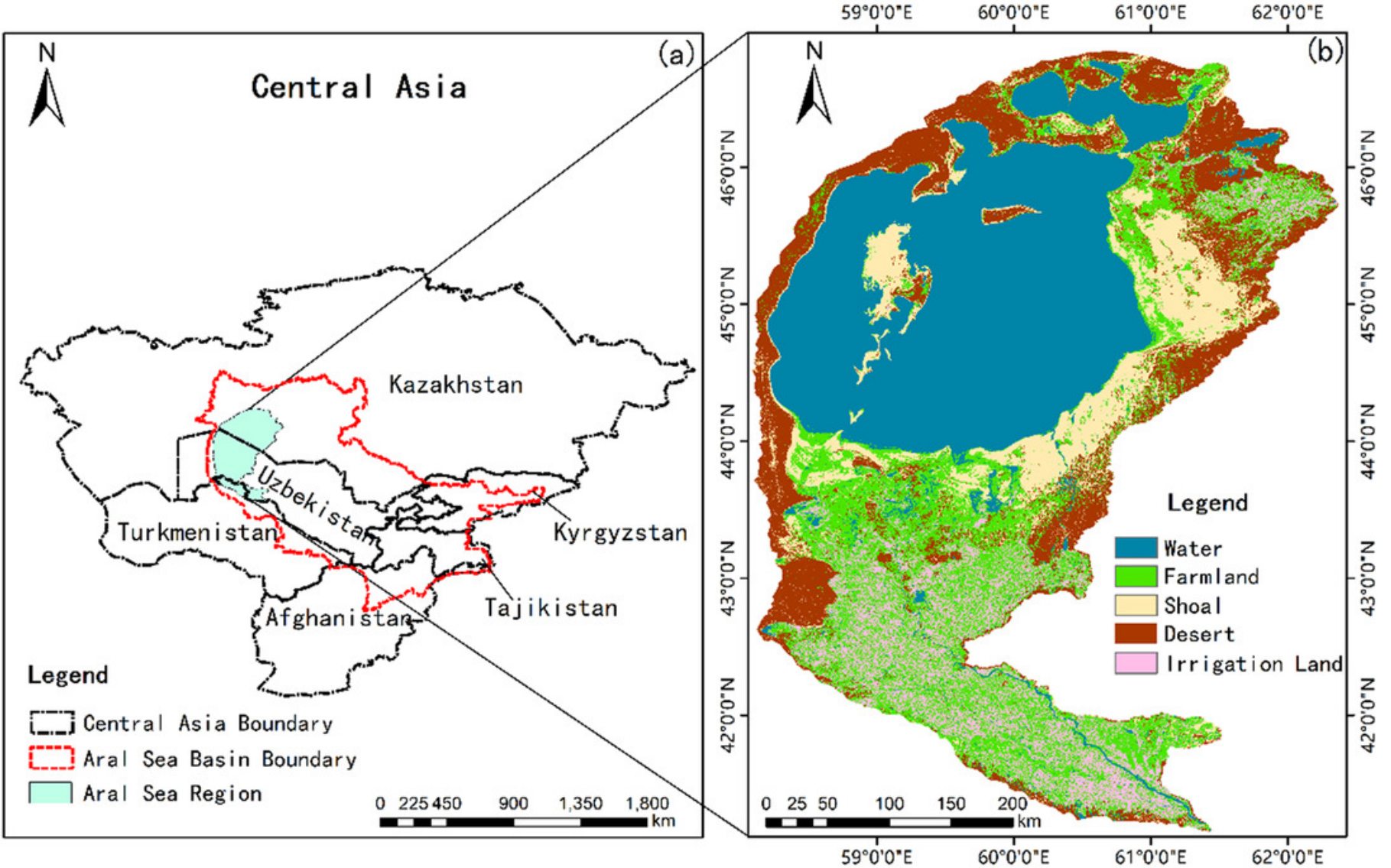


Figure 2

Research Method

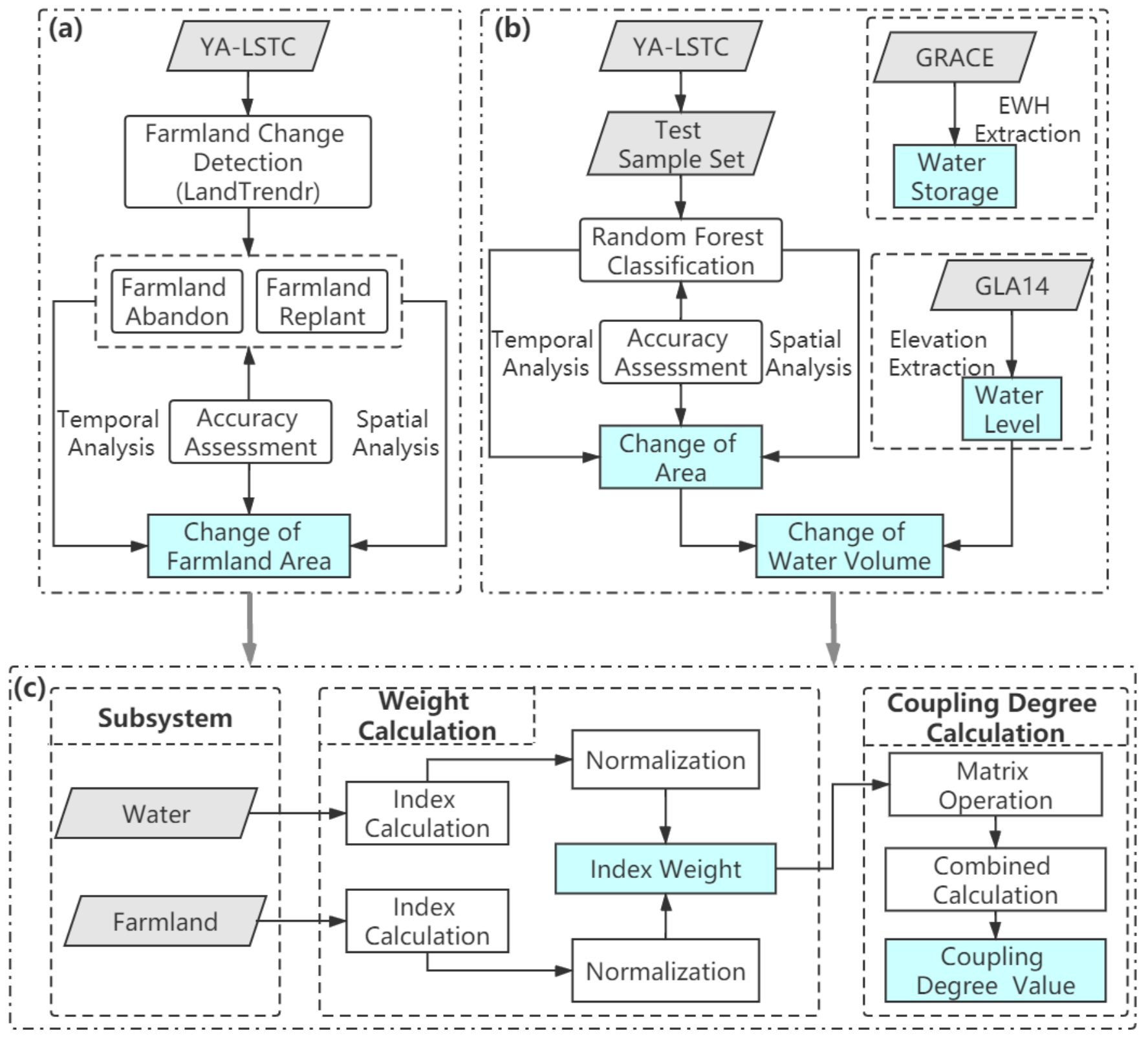




\section{Figure 3}

Examples areas of water change and farmland change near the Syr Darya and the Amu Darya. Figures a1 and a2 represent the water change years 2009 and 2019; Figures b1, b2, b3 represent the water change years 2009, 2016 and 2019

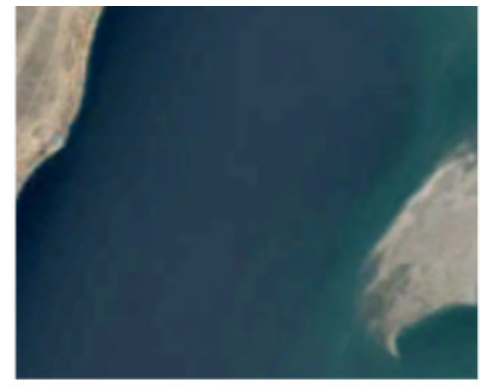

(a1)

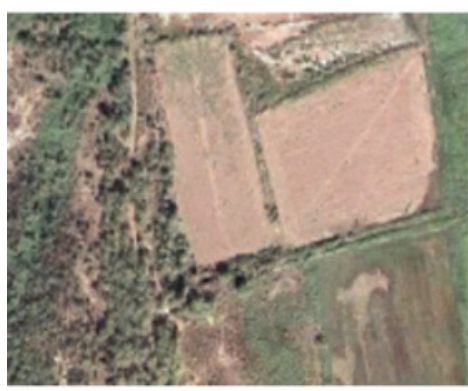

(b1)
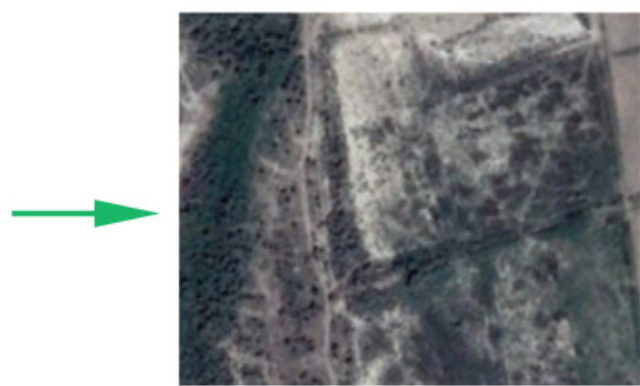

(b2)

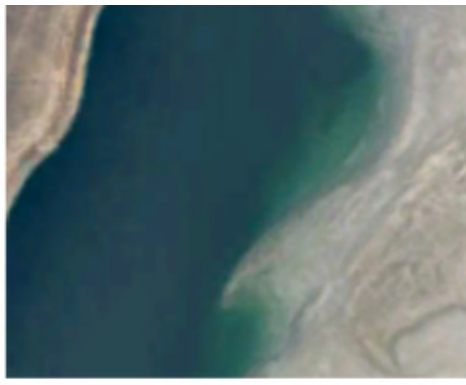

(a2)

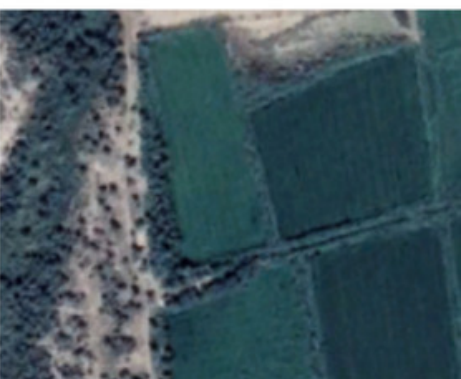

(b3) 
Figure 4

Year of abandoned farmland in the Aral Sea Region with two areas shown in detail
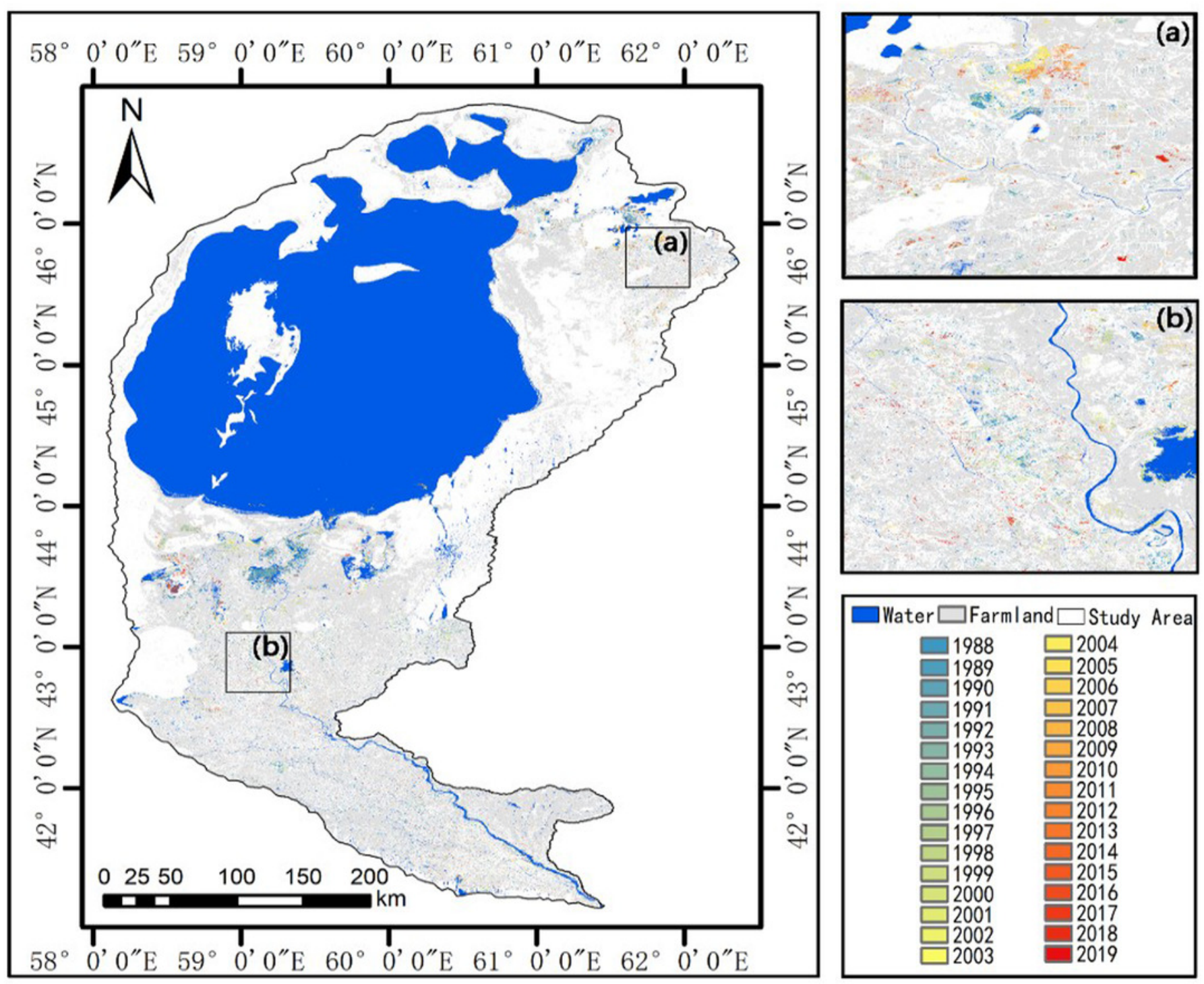

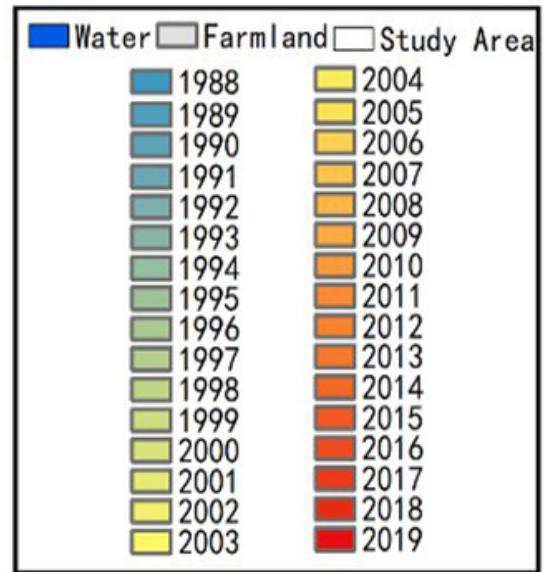


Figure 5

Change of the Aral Sea area from 1987 to 2019
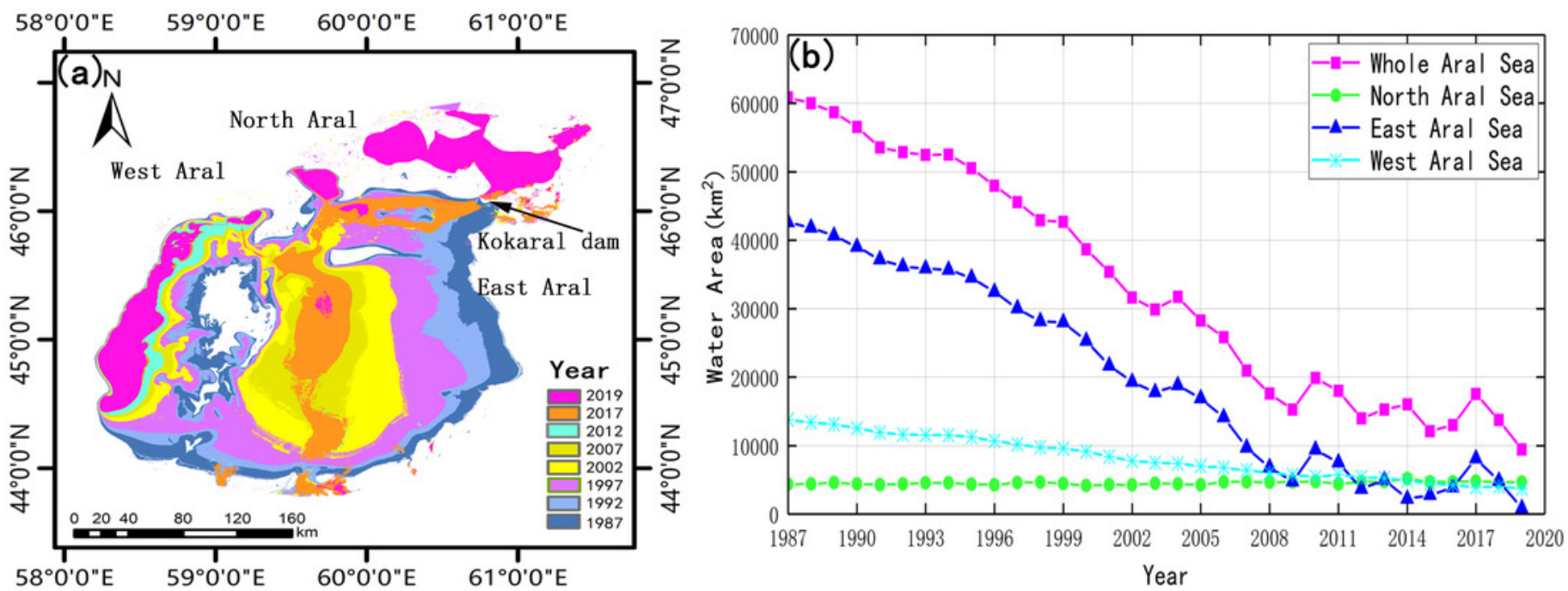
Figure 6

Change of the Aral Sea water level from 2003 to 2009

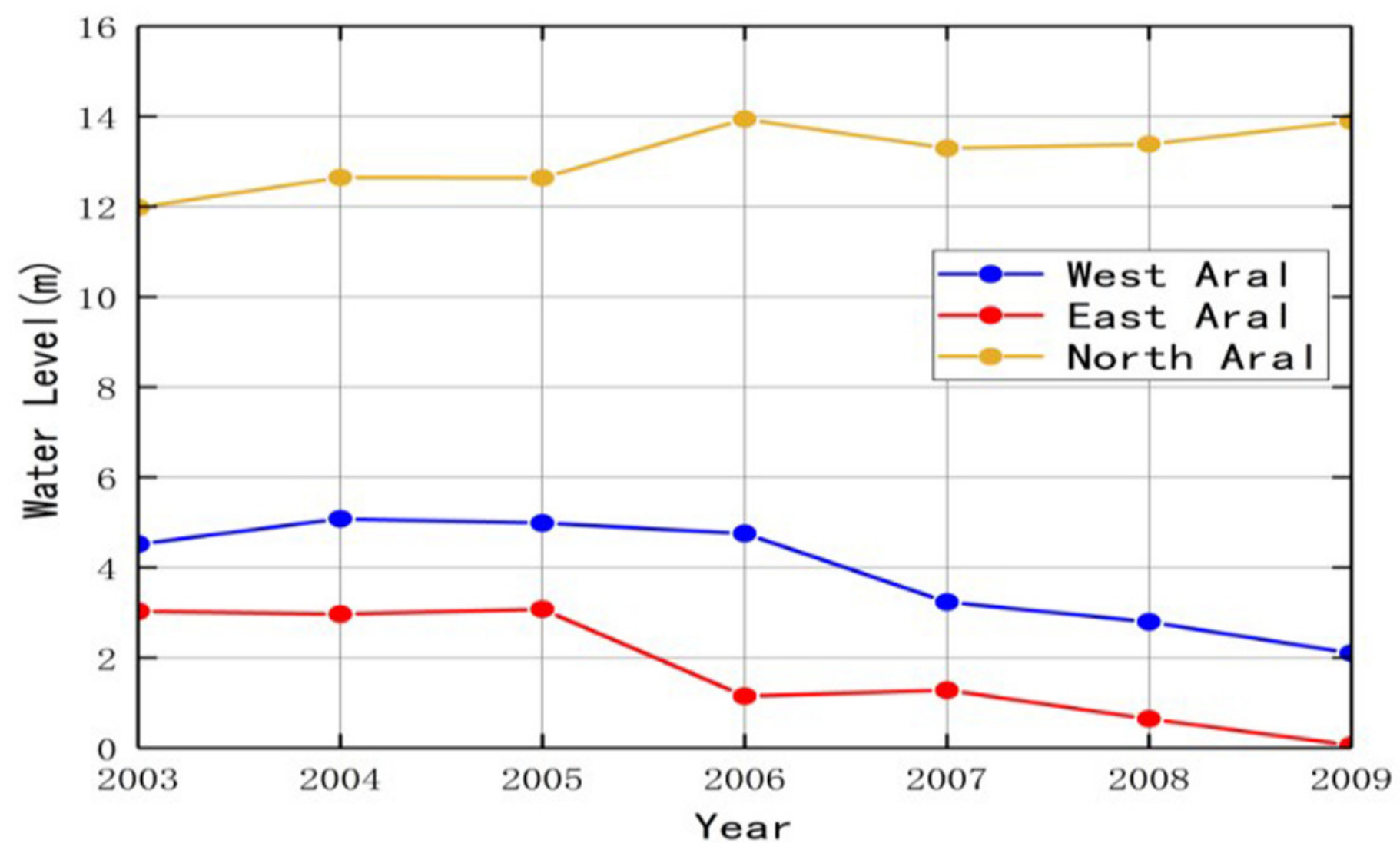


Figure 7

Mass change of the Aral Sea Region from 2002 to 2016

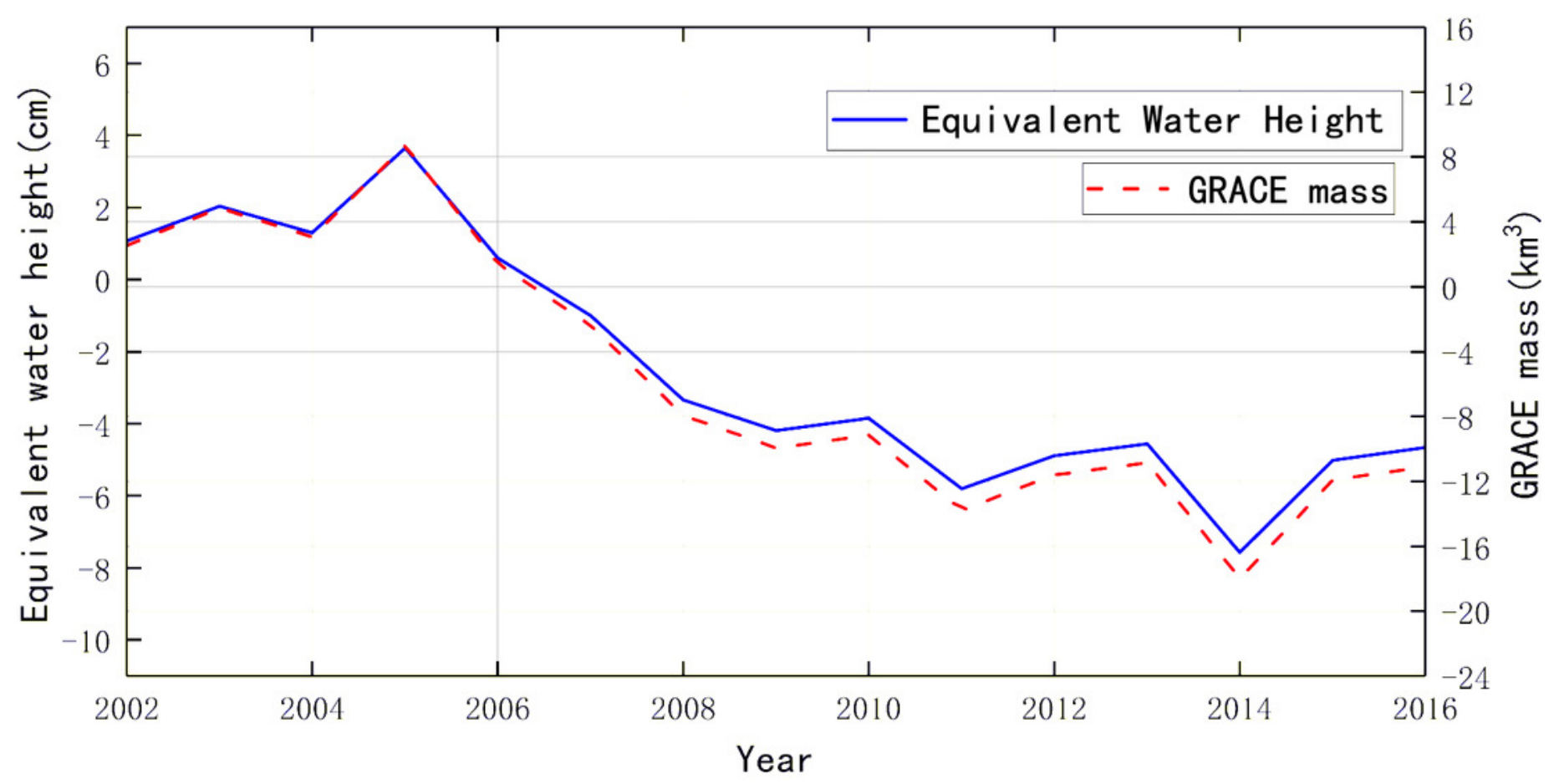

